\title{
The Role of Community-Based Organizations in Management Access and Success of Public Administration Development Empirical Analysis in Front of Theory-Cal Analysis
}

\author{
Prof.Assoc. Dr. Alba Dumi \\ Director of Graduate School, "Ismail Qemali" Vlore University, Albania, Business Department, \\ Email:alba.besi12@gmail.com \\ Ma.sc. Isuf Jahmurataj
}

Student in PhD studies at the South East European University Faculty of Law, direction of Civile Law"

Prof Inestiss Siagniliss

Eiprius TAE University Business Department, Athena Grecce

Msc Denisa Maze

Doi:10.5901/ajis.2014.v3n3p457

Economy Faculty Tirana Business Department Albania

\begin{abstract}
This study examines the legal framework for municipal governance and analyses whether, in practice, the relationships follow the pattern as intended in the law. More than thirty interviews were conducted with office-bearers, councilors and officials in five municipalities which differed according to size, location and success levels. In recent years, leaders of development cities have become progressively concerned, about increasing the college-going and completion rate of their residents. Development other cities have launched initiatives to increase college completion rates, mobilizing stakeholders from the education, non-profit, and corporate sectors to share responsibility for achieving these goals. To a large extent, efforts to increase college-going and completion rates have focused on making-changes in education systems to ensure that young people finish high school ready for college and complete degrees in a timely manner. But, today there is growing recognition of the important role that community-based organizations (CBOs) can play in supporting young people's postsecondary aspirations and success Business takes place worldwide, in a huge diversity of societies and between widely varying organizations. Actually, the business environment has become more complex, with expanding and deepening ties between societies and between the many organizations within those societies. Moreover, many large organizations now see themselves as truly global in scope, not rooted in any one society. This study empirically examines the impact of debt management policies on borrowing costs incurred by state governments when issuing debt in the municipal bond market and it is in focus of public administration reforms.
\end{abstract}

Keywords: Albanian situation, foreign investment; roles of governments; European Community;

\section{Introduction}

The aim of this article is to present an overview of the international environment, highlighting the differing levels, from local and national, to regional and international. The discussion focuses on the main identifying features of the business organization, including ownership and decision-making structures, as they adapt in differing geographical contexts. It is emphasized that the multinational enterprise (MNE), central to international business activities, covers a variety of organizations, large and small and the growing interactions between organizations, governmental and societal players are resulting in a broader view of the business organization in society. This argument looks at varying perspectives on globalization, often argued to be the defining characteristic of our times.

Albania is open to foreign investment and increasing FDI is a top priority for the Albanian Government. Albania has put in place a liberal foreign investment regime, including a 10 percent flat corporate and income tax and has taken measures to improve the business climate by streamlining business procedures through e-government reforms. These improvements along with NATO membership and progress toward EU integration have contributed to the increase in 
invests interest during the last couple of years. Promising sectors for foreign investors and include: energy (including alternative energies), mining, transportation, telecommunications, and tourism.

\subsection{What are community-based organizations and why are they important?}

CBOs are public or private, nonprofit organizations engaged in addressing the social and economic needs of individuals and groups in a defined geographic area, usually no larger than a county. The college access and success efforts of CBOs vary, depending on their mission and vision. For example, direct service organizations provide college information, advice, and application assistance to individual students and families; organize college awareness workshops, financial aid nights, and college fairs; and support students in high school through their college years.

H1. Youth development organizations often offer extended learning opportunities such as traditional after-school activities with an academic focus, apprenticeships and internships, summer enrichment and travel, and activities on college campuses.

Integrated student services organizations work with schools to identify and assist individual students needing support with academic issues and non-academic problems that interfere with their school achievement averaging resources from appropriate agencies, including health care, social services, and counseling. Finally, community mobilization coalitions consist of public and private entities focused on systemic change to achieve an overarching community-wide goal such as doubling the number of high school graduates or improving college completion within a specified time period. (Source: Root Cause, Colliner A, 2011)

The strategic country's geographic position places it at the crossroads of Western and Eastern Europe makes it a stable U.S. ally, a member of NATO, the WTO and a probable candidate status in the European Union. Although FDI has increased during the last couple of years, it still remains among the lowest in the region with a significant part of it coming from privatizations. Despite progress in reforms the major factors hindering FDI seem to remain the same: widespread corruption, weak law enforcement, insufficiently defined property rights, lack of developed infrastructure, a sluggish government bureaucracy and frequent changes in the legal framework. (Bennet S \&Dolann F 2011 MSCER)

Having autonomy is very important to employees. People have a strong need to control their lives and to participate in making decisions that affect them. In my own research I found that autonomy was related to higher levels of job satisfaction and commitment and fewer thoughts of quitting. In cultures of caring leaders understand that their job is to create conditions where people thrive, not to control their every move. (Cabrerra B 2011)

In addition to autonomy, people also need to feel that they have the support necessary to succeed. Clarifying expectations and giving people control over how they achieve their goals isn't enough. Leaders need to clear the path, getting rid of barriers that stand in the way of goal achievement. Their role should be to empower others by serving their needs and making sure they have the resources required to get the job done.

\subsection{Structural Features and Partnership system}

Partnerships and cross-systems collaboration: work with schools, higher education institutions, families, and other community organizations to address students' diverse needs and smooth the transition from high school to college. Strategic use of time: using after-school, weekend, and summer time for experiences that will expand students' sense of possibilities, accelerate learning in core subject areas, and keep them on track toward reaching college goals.

Leadership and autonomy: competent and tenacious leaders and the independence to act quickly and strategically to meet students' needs.

\section{Autonomy Helps Employees Be Self-Motivated}

As a charismatic leader, you can help employees be self-motivated and earn their discretionary effort by turning the focus of employee motivation from hard results and productivity numbers tied to rewards to employee autonomy and employee learning.

It makes no sense to hire an employee for their skills, knowledge, and intellect, then micromanage their every move. It makes good sense to give the employee parameters, conditions and a vision of the finished product and invite the employee to share their ideas. At this point, if you feel the employee understands the project and what the end product should be, permit the employee to operate autonomously within the parameter you have set. The employees feel empowered as they exercise influence over the decisions that affect them personally, assert control over the project and make crucial decisions. Giving the employee autonomy to make decisions is a form of reward for consistent and reliable 
behavior.

It also provides phenomenal learning and growth experiences. I learn quickly and deeply when I need information to solve a particular problem. When employees are immersed in a project, operating autonomously and MUST have answers to challenges to complete the project, they will learn rapidly, finding viable alternatives and exploring feasible options. This learning builds competence and self-esteem. (Brendeau K)

You reward? You will have a gift of time to focus on the future as your employees provide their own internal motivation through the opportunity to operate autonomously. The by product is retention of your best and brightest.

Effective assessment and use of data: continually compiling and using information on students' backgrounds, participation and progress to determine program effectiveness and make changes as needed. (Source: Root Cause, 2011)

Positive organizations create cultures of caring based on the belief that everyone who comes into contact with the company should be better off because of it. This includes employees. Companies demonstrate concern for their employees' well-being by actively attending to their needs. Two key employee needs are autonomy and support.

Foreign companies continue to face significant challenges in entering the market, particularly in areas that touch on property rights. Despite advancements government bureaucracy and inefficiency greatly hampers the ability to hold successful, open and transparent government tenders. They are under-equipped to handle essential tasks. These are primarily to manage transition, provide the regulatory/administrative framework for the market, establish relations with the international community and negotiate and manage aid flows. But these tasks must be carried out while re-establishing order and maintaining social safety nets, under conditions of budget stringency. (Dumi A. AJIS 2012)

\section{The Importance of this Study}

This study empirically examines the impact of debt management policies on borrowing costs incurred by state governments when issuing debt in the municipal bond market. Based on positive political theory and the benefit principle of taxation, it is proposed that states that adhere to best practice debt management policies transmit signals to the credit ratings, investment community and taxpayers that the government should meet its obligations in a timely manner, resulting in lower debt costs. As a result (USA political debt and reforming policies) of a multi-block multivariate regression model the implication of adhering to debt policies aimed at promoting transparency results in a borrowing cost savings in terms of true interest cost (TIC). However a comprehensive debt policy is not a significant indicator of borrowing costs. These results suggest a product of a pull-push process between the economic forces of the bond market on one hand and politics on the other, pulling the administrative function toward efficiency in the former and democratic values of responsiveness and transparency in the latter.

The problem lies in policies that respond to the bond market but virtually exclude any other community interest in policy making. It is recommended that openness in government and allowing taxpayers to understand government services are essential goals in ensuring responsible citizen oversight and providing taxpayers the opportunity to be less likely to propose restrictive initiatives or force dramatic political or management changes through the electoral process or bond referenda.

\subsection{Albanian Local Government Programs and Projects}

Refers to European Community, the difference of single states policy applied to grow the own international trade, are small. What is the real situation in states not members of European Community, like Albania, according to international business environment? The external environment includes an array of dimensions, including economic, political, legal and technological factors. The article analyses their impacts on societies and the environment, and considers the roles of governments and firms in the wider stakeholder context.

Naturally, at the end of this article we will have a complete vision of Albanian situation. We are going to illustrate the nature of globalization, highlighting trends in globalized production and market, by contrasting the key features of foreign direct investment (FDI), foreign indirect investment and other modes of international operations.

The whole Society and Albanian Local Government Support Program (CSLGP) aims to increase the level of informed and organized civic activism at the local and national levels, along with more participatory, decentralized, accountable governance that leads to a more democratic society. 


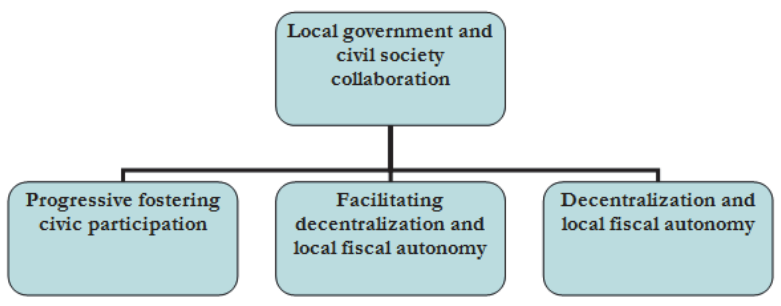

Source: European Court of Human Rights (ECHR, 2014) Hooker, Sara and Betsy Brand. 2009. Programs Support Youth on the Path to College and Beyond. Washington, DC: American Youth Policy Forum.

The Access to Information for Albanian Community Involvement program focuses on: (1) Training of public officials, local government representatives and civic groups on freedom of information, (2) Media outreach to inform and update the public and the government on freedom-of-information, (3) production of a freedom-of-information (FOI) website; (4) Improving mechanisms for proactive publication of government-held information; and (5) free legal counseling to citizens and community organizations on FOI. The project will reach this objective through three programmatic components: (1) local government and civil society collaboration, (2) fostering civic participation, advocacy and activism, and (3) facilitating decentralization and local fiscal autonomy. Project aims to support Albania rapprochement through developing new business partnerships and regional professional networks; engaging civil society in alliance-building to further contribute to Albania normalization; and supporting government and non-government efforts toward rapprochement with research. (SJA 2010. College Access and Success: Education and Youth Development. Cambridge, MA: Root Cause)

\section{Organizing the Effort by Developing a Management Team and Partnership Network}

- Mayor and the body of councilmen must take pride in knowing their community and its residents.

- Community goals/image are constructed and must be visible to members of the community.

- Level of Organization and Full Democratic Representation: Representative organizations are necessary to serve as a forum for persons to give input. It is also important to determine the interests of each segment of the population.

- Political Will: Local authorities must demonstrate the political will to carry out the plan, i.e. A readiness to set objectives and to accomplish them.

- Availability of Basic Resources: Resources and funds are necessary.

- Objectives achieved and assumed by the population: The organization needs to have ownership of achievable objectives that combine individual interests with those of the community.

- Social sector defined in and for each objective: Each development objective has to have its social subject defined.

- Schedule of Activities: The plan must be concrete, with dates and deadlines set in advance and publicly announced.

- Permanent Evaluation: The performance, accomplishments, progress and failures must also be public to lay the foundation for new objectives and participation practices.

Information and Transparency: Information is the most secure basis for transparency in public life.

\subsection{Rule of Law Albanian Development Program core programmatic objectives include: (1) increasing the judiciary's}

knowledge of the European Court of Human Rights (ECHR); (2) enhancing the institutional capacity of the Independent Bar Association; (3) improving the quality of legal education; and (4) fostering an effective environment for human rights protection. Administrative changes in Albanian public policies as an obstacle to the operating foreign investments, comparison of EU like these factors: A dynamic local government leadership;

- A healthy climate of cooperation with business;

- Improving the quality of legal rules;

- Local government's investment initiatives to jumpstart the stagnant economy;

- Creative use of EU funds to implement local policy; 
Efficient municipal administration;

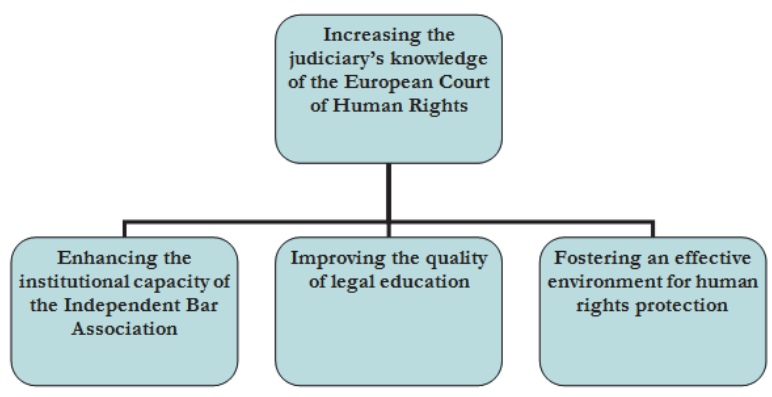

Source: European Court of Human Rights (ECHR, 2014) Hooker, Sara and Betsy Brand. 2009. Programs Support Youth on the Path to College and Beyond. Washington, DC: American Youth Policy Forum.

\section{Institutional Mission}

- Promote economic development of the city.

- Efficiently provide public services.

- Administers funds to raise the population's standard of living.

- Regulate activities such as healthfulness of district and its ecological conservation.

\section{Objectives}

These results suggest a product of a pull-push process between the economic forces of the bond market on one hand and politics on the other, pulling the administrative function toward efficiency in the former and democratic values of responsiveness and transparency in the latter. The problem lies in policies that respond to the bond market but virtually exclude any other community interest in policy making. It is recommended that openness in government and allowing taxpayers to understand government services are essential goals in ensuring responsible citizen oversight and providing taxpayers the opportunity to be less likely to propose restrictive initiatives or force dramatic political or management changes through the electoral process or bond referenda.

The external environment includes an array of dimensions, including economic, political, legal and technological factors. The article analyses their impacts on societies and the environment, and considers the roles of governments and firms in the wider stakeholder context.

The principal arguments treated. Through its programs in the areas of anti-corruption, local governance, rule of law, alternative media, and parliamentary assistance, USAID is working with civil society and reformers within the Government of Albania to help create opportunities that helps Albania to advance the country's democratic reform both at the local and national levels. Based on an "active citizen" approach to democratic development, USAID is broadening efforts to foster greater citizen participation at the grassroots level and strengthening advocacy NGOs by providing core funding, advocacy grants and tailored technical assistance.

\subsection{Analyses selected indicators for responsiveness of public administration}

The business environment may be visualized in terms of layers, beginning with the immediate internal environment within the organization, and moving outwards to the external environment surrounding the business and influencing its organization and operations. While only a few decades ago these external aspects were seen as centering on the home country of the business, the environmental horizon of business has now widened to take in a host of international forces, which interact with national and local factors.

Tensions exist between an organization and the external forces that impact on it, from local through to international, and these tensions are reflected in its internal environment.

For this, when we think of international business, we tend to think of large multinationals, but most of the world's businesses are very much smaller, and, increasingly, these smaller firms are becoming international in their outlook. 
Nowadays, thanks to advances in communication technology and transport, it is easier for companies to expand a variety of business activities across national borders. A large American corporation such as IBM may seem to have very little in common with a family-run firm in Tirana that selling its products or purchasing raw materials abroad, and go on to producing its products abroad. Even if their answers on how to achieve a smooth-running and efficient organization and how to satisfy the needs of customers may be different, both companies in their own way will affronting universal issues.

Like we know in the past the most important factors which influenced the firms were cultural and social, legal and technological factors. Now the factors which compose the economic policy and influenced international environment are not so unpredictable. The problem is that are complicated for the different decision making stakeholders at a time of a stagnant economy.

\section{Methodology}

From the interviews, it is clear that role confusion exists between the various organs within municipalities. This has lead to uncertainty and turf battles, shifting the energy of the council to technical issues and impeding efficient service delivery. Municipalities have not been sufficiently able to design and implement role divisions and agree on workable protocols. Local government legislation establishes various organs within the municipality and broadly defines the functions of these organs. It also creates various instruments for accountability and oversight. Importantly, municipalities themselves must define the precise roles of their organs in delegations and terms of reference. These role definitions, terms of reference and instruments of accountability are intended to produce clear and sound internal municipal governance arrangements. This, in turn, is meant to define and shape the relationships within the municipal council and between the council and the administration.

The research methodology used to complete this article is that to compare the latest international economic policies to respond to different features present or not in them. To pursue this purpose we will use as a reliable research sources such as the European community, the Ministry of Economy of Albania, etc. Albanian companies act in an environment that is more or less favorable to them. The environment is significantly limited by the institutional framework that the rules of the game and is controlled by public administration and is responsive to the needs of foreign companies.

In the empirical part of the paper, we analyze selected indicators for responsiveness of the public administration in selected Albanian programs, compared European Union (EU).

\subsection{The real situation of financial sector in Albania}

The financial sector in Albania has in general been spared from the global financial turmoil, primarily due to the low amount of loans in relation to total deposits. Also the lack of a housing/construction bubble has minimized pressure on the banks. However, a significant reduction in bank deposits took place in the fall of September 2008 as individuals withdraw their money due to fear from losing their savings. Since October 2008 deposits dropped by about 15\% and during 2009 they were below their top level. After summer 2009 there has been a stable increase in bank deposits and by the end of 2009 they reached their pre-crisis level.

\begin{tabular}{lcccccc}
\hline & Mesatarja & Mediana & Maksimumi & Minimumi & D.standart & Nr.vezhgime \\
Pbb_real & 826.2 & 782.9 & 1400.9 & 346.4 & 346.4 & 18 \\
Pdebt_real & 477.8 & 446.05 & 872 & 116.3 & 217.4 & 18 \\
Real_egrowth & 5.2 & 5.5 & 13.9 & -11.8 & 26.1 & 18 \\
Pdebt_real_percent & 56.8 & 58.7 & 63.4 & 33.6 & 6.7 & 18 \\
Pinternal Debt_percent & 36.9 & 37.9 & 43.2 & 23.9 & 4.4 & 18 \\
Pextrenal Debt_percent & 19.2 & 17.6 & 28.4 & 9.7 & 4.6 & 18 \\
\hline
\end{tabular}

\begin{tabular}{|c|c|c|c|}
\hline Koeficentet & 2.834811 & -39.6484 & \multirow{2}{*}{} \\
\hline Devijimi standart & 0.139517 & 45.47917 & devijim standart per $Y$ \\
\hline$R^{2}$ & 0.962691 & 69.53546 & Shkallët e lirisë \\
\hline F & 412.8511 & 16 & RSS \\
\hline RSS totale & 1996209 & 77362.88 & \\
\hline
\end{tabular}

\begin{tabular}{|c|c|c|}
\hline testet t & & \\
\hline $\mathrm{X}_{1}$ & 20 & Pranoj Ho \\
\hline $\mathrm{Y}$ & 4.26 & Pranoj Ho \\
\hline
\end{tabular}



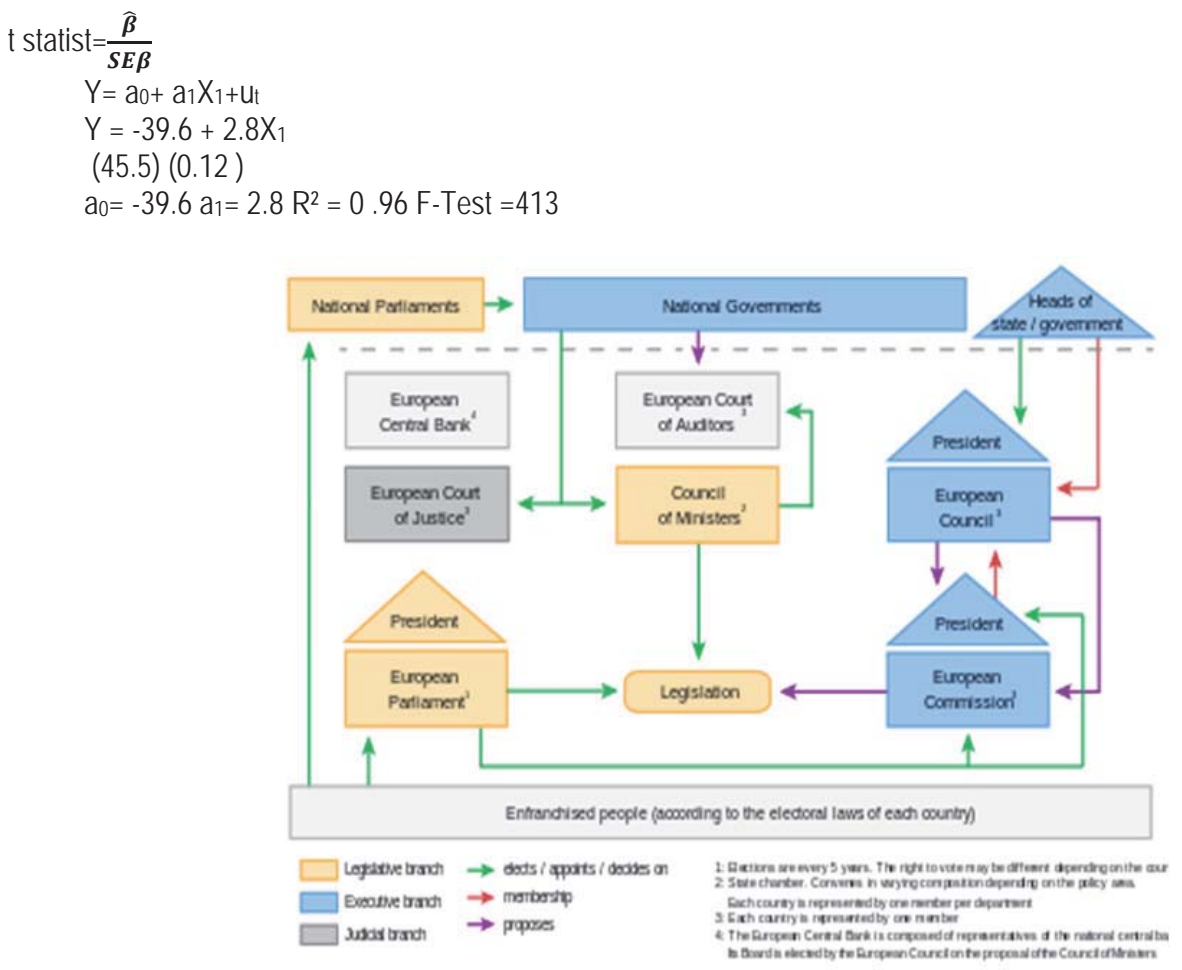

Lower deposits created some liquidity issues but banks were well equipped to face the situation. Banks have increased their equity capital to better face the situation and also BOA has an active monitoring program to ensure enough liquidity in the banking sector. The financial sector is totally dominated by commercial banks funded with private capital. Currently, 16 banks are operating in the country - two domestically owned banks and 14 foreign or joint ventures.

\begin{tabular}{|c|c|c|c|}
\hline Koeficentet & 2.96756 & 309.626 & \multicolumn{1}{|}{} \\
\hline Devijimi standart & 0.22866 & 46.7481 & err.std per vleresimin e y \\
\hline R & 0.91325 & 106.034 & shkallet e lirise \\
\hline F & 168.428 & 16 & RSS \\
\hline RSS totale & 1893680 & 179893 & \\
\hline
\end{tabular}

$Y=a_{0}+a_{1} X_{2}+u_{t} Y=309.6+2.96 X_{2}$

(46.7) (0.2)

$a_{0}=309.6 a_{1}=2.9 R^{2}=0.91$ F-Test $=168$

Referring to the above mentioned financial crisis which influenced companies stocks, we can say that, Albanian companies have little or no influence. This, not only for the mentioned reasons above, but because only $3 \%$ of the Albanian companies are with private capital trading in stock exchange, the rest are joint stock companies with public capital.

\subsection{Foreign Direct Investment Statistics}

The FDI has increased although it still remains among the lowest in the region. The cumulative FDI is also the lowest in the region. The Bank of Albania reported the following figures for foreign direct investment in Albania. Regardless of numerous contracts, only a few projects materialized in 2009. 


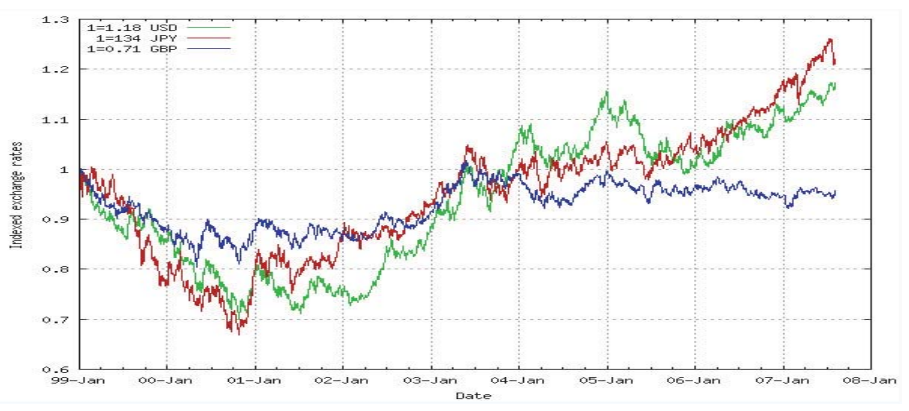

Source: Bank of Albania BA estimate for the first three quarters of 2009, 2010

\section{The Direct Investiments in Albania in 2009-2010}

FDI during the first nine months of 2009, 2010 is estimated to have reached 580 or 588 million euro despite optimistic GOA projections for 2009 fueled mainly by strong investor interest witnessed during 2007-2008. A large part of FDI is due to privatizations. The Albanian government collected 103 million Euro from the privatization of 76 percent of the shares of the distribution arm of Albanian Power Corporation; 48 million Euro from the privatization of 12.6 percent of AMC state controlled shares; 5 million euro from the privatization of $40 \%$ of GOA controlled shares of the United Bank Albania. INSIG (insurance company) privatization failed during the negotiation process with the winner and it might take place during 2011.

\subsection{Public Debt and Albanian Situation}

Analyzing the relationship between economic shocks and public debt that is having lately the European Community (we refer in particular to the crisis of the GDP of the two member states like Greece and Italy) budgeting decisions in the context of local economic shocks reveal the local fiscal policy priorities. The analysis of Albanian incomes, finds that current expenditure paths are more influential when making cuts than when expanding budgets.

H2. Public Strategies employees strive to support and improve the communities in which they live and work.

The government support programs that help those in need who strive to provide for their families; and provide the youth of the community with the tools necessary to become leaders. Also focus on two primary areas to ensure the company provides meaningful contributions to the community. Our corporate contributions of time and money go to promoting philanthropy and to youth leadership development through initiatives that produce measurable outcomes and sustainable results in these two areas.

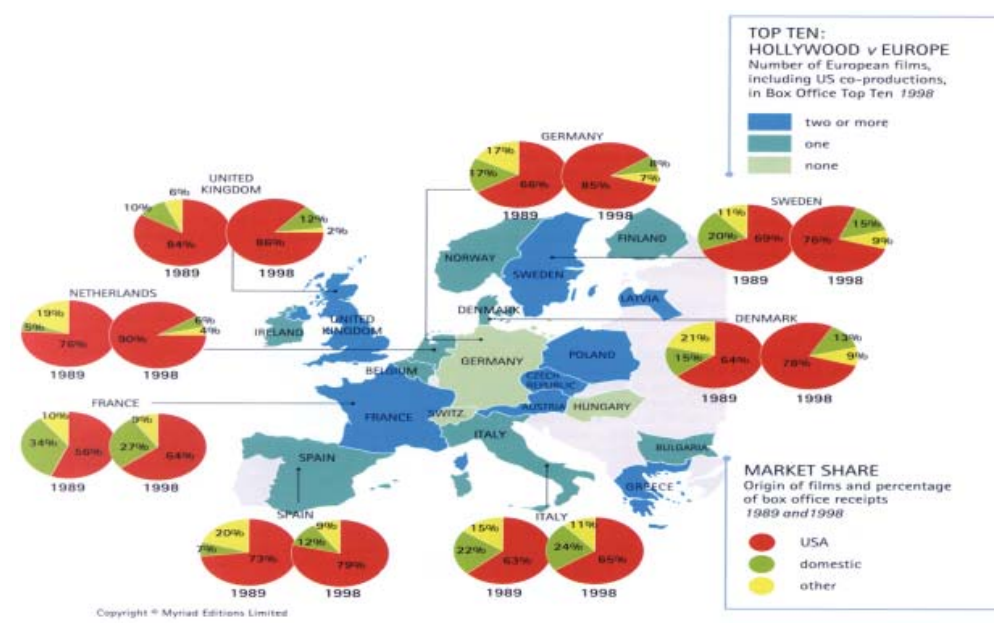


Government regulations applied to counties, like Albania once classified as not in attainment of ambient air quality standards affect local tax bases. Local communities are also seen to employ some short-term use of reserve funds when facing negative expenditure pressures, but these funds are not used to completely prevent expenditure cuts. Furthermore, communities do not use debt as a mitigating response to external tax base pressures, but instead alter expenditure patterns.

\section{Conclusions and Recommendation}

Administrative changes in Albanian public policies as an obstacle to the operating foreign investments, comparison of EU are progressed in Albania like as:

- Developing;

- International investments founds;

- Entrepreneurship ambition;

- Marshalling resources to exploit business opportunity;

- State regulatory statistical and tax reporting.

Local communities are also seen to employ some short-term use of reserve funds when facing negative expenditure pressures, but these funds are not used to completely prevent expenditure cuts. Furthermore, communities do not use debt as a mitigating response to external tax base pressures, but instead alter expenditure patterns. Using the EU measurements and assessment of different areas of the business, namely the production of goods and services, can take place smoothly in Albania. PSI worked closely with high-level public officials and community leaders and provided critical guidance and strategic planning. On an ongoing basis, PSI continues to adapt to: the changing needs of the communities we serve, legislative and administrative directives, research findings and promising practices from the field. These efforts include:

- Providing customized training and learning opportunities for partners;

- Managing the daily activities of project staff;

- Monitoring large-scale project implementation benchmarks;

- Monitoring the new opportunities of developing and LC of new business;

- Manage the human resources, youth and women.

Additionally, PSI conducts field research that may lead to adjustments to the program in order to meet greater project goals. This has resulted in a high level of trust with state officials and more effective service delivery because program adjustments are made in a timely manner.

\section{Results and Profits from this Research}

Administrative changes in Albanian public policies as an obstacle to the operating foreign investments, comparison of EU. This includes partnerships with community-based organizations, public and private colleges, universities, public school teachers, public health departments. Additionally, more number of community leaders have been trained to deliver educational workshops; PSI has developed a robust workshop leader database, which permits remote access to (and entry of) service delivery information. This will be an important point of administrative changes in Albanian public policies as an obstacle to the operating foreign investments, comparison of EU.

Entrepreneurship ambition has worked to support changes in Albanian law that would offer anti-discrimination protections in keeping with international standards. The another point of administrative changes in Albanian public policies as an obstacle to the operating foreign investments, comparison of EU is: (1) International investments contributed to the improvement of Albania's financial regulatory environment which has strengthened public confidence in the banking system and has provided a more secure, efficient and transparent financial system to meet the credit, savings and insurance needs of businesses and individuals.

\section{Results of Paper Research}

Local government legislation establishes various organs within the municipality and broadly defines the functions of these organs. It also creates various instruments for accountability and oversight. Importantly, municipalities themselves must define the precise roles of their organs in delegations and terms of reference. These role definitions, terms of reference and instruments of accountability are intended to produce clear and sound internal municipal governance arrangements. 
This, in turn, is meant to define and shape the relationships within the municipal council and between the council and the administration. Whatever cannot be solved in strictly institutional or legal terms needs to be solved through agreed protocols, gentleman's agreements and working arrangements.

The result is a carefully crafted system of governance and oversight whose success is dependent on all constituent parts working in sync. Practically, if one component of the system is deficient, it has a detrimental knock-on effect which ultimately impacts municipal service delivery.

From the interviews, it is clear that role confusion exists between the various organs within municipalities. This has lead to uncertainty and turf battles, shifting the energy of the council to technical issues and impeding efficient service delivery. Municipalities have not been sufficiently able to design and implement role divisions and agree on workable protocols.

\section{References}

Aulicino Claire and Donna Tapper. 2008. The College-Community Connections Program: Implementation and Influence of Unique PreCollege Experiences for New York City Youth.

New York, NY:p://rootcause.org/college-access 12http://rootcause.org/college-access

Social Issue Report. 2010. College Access and Success: Education and Youth Development. Cambridge, MA: Root Cause.

Allen, Lili. 2010. Mobilizing a Cross-Sector Collaborative for Systemic Change. Boston, MA: Jobs for the Future.

Banka e Shqipërisë (2010), "Raporti Vjetor 2010", f 41 URL: http://www.bankofalbania.org/web/Raporti_Vjetor_2010_6172_1.php

Banka e Shqipërisë (1997): "Raporti Vjetor 1997", f 13 URL:http://eduarto.tripod.com/sitebuildercontent/sitebuilderfiles/raportivjetor 1997.pdf

Coëan et al (2006): "Sovereign Debt in the Americas: Data and Stylized Facts", f 4 URL:http://ëëë.iadb.org/res/publications /pubfiles/pubËP-577.pdf

Cipiku \& Mittitelu, Workshop on "Public Administration in the Balkans - from Weberian bureaucracy to New Public Management" 2010 